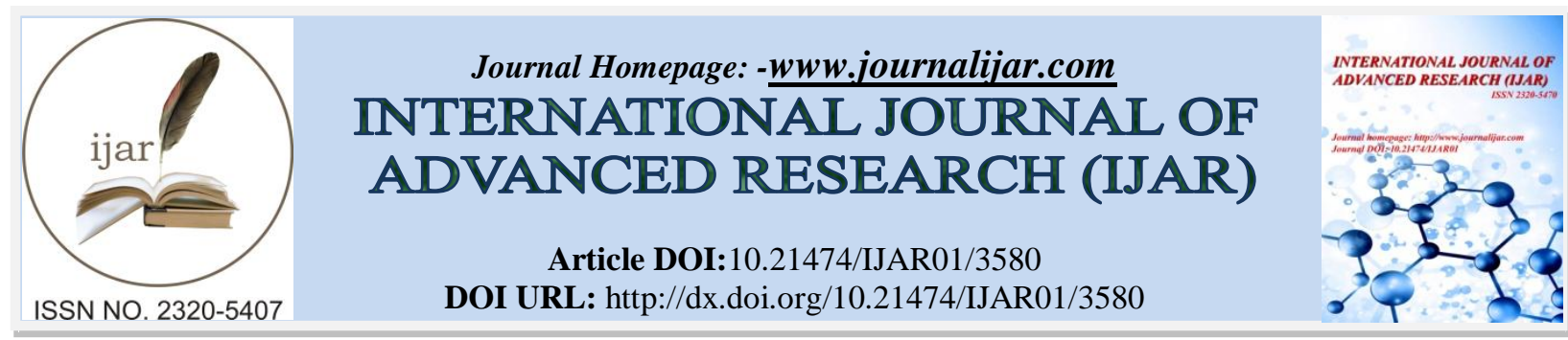

RESEARCH ARTICLE

\title{
UPDATE ON THE BIOMARKERS FOR TARGETED THERAPY IN TRIPLE-NEGATIVE BREAST CANCER.
}

\author{
${ }^{1}$ Ibrahim Abdullah Al Balawi MDFRCSI ${ }^{1}$ and Tahir Ahmad Mir BDS ${ }^{2}$. \\ 1. Department of surgical oncology, Faculty of Medicine, University of Tabuk, Kingdom of Saudi Arabia. \\ 2. Inderprastha Dental College \& Hospital, Industrial Area, Sahibabad ,Ghaziabad, U.P- 201010 India.
}

\section{Manuscript Info}

Manuscript History

Received: 04 January 2017

Final Accepted: 05 February 2017

Published: March 2017

\begin{abstract}
Breast cancers that demonstrate the absence of estrogen receptor and progesterone receptor and no overexpression of human epidermal growth factor receptor 2 (HER2) are referred to as triple-negative breast cancer (TNBC). Globally 1 million cases of breast cancer are diagnosed annually and Triple-negative breast cancer comprises 15\%$20 \%$ of all breast cancers. The last decade has seen a revolution in the understanding of breast cancer, with new classifications proposed that have significant prognostic value and provide guides to treatment options. There are many biomarkers in TNBC used for its subclassification. Clinically-practical assay/biomarkers that can reliably identify TNBC are necessary. Biomarkers may be useful as prognostic or predictive indicators as well as suggest possible targets for novel therapies.
\end{abstract}

Copy Right, IJAR, 2017,. All rights reserved.

\section{Introduction:-}

Triple-negative breast cancers (TNBCs) are defined by the absence of estrogen and progesterone receptors and the absence of HER2 overexpression. These cancers represent a heterogeneous breast cancer subtype with a poor prognosis. In 2012 about 1.7 million women worldwide were diagnosed with breast cancer (BC), and 521,900 women died from it.(1-2) TNBC represents 10\%-20\% of invasive breast cancers and has been associated with African-American American race, deprivation status, younger age at diagnosis, more advanced disease stage, higher grade, high mitotic indices, family history of breast cancer and BRCAlmutations. TNBC is regularly reported to be three times more common in women of African descent and in pre-menopausal women, and carries a poorer prognosis than other forms of breast cancer. (3) These statistics include all subtypes of BC, but it is well known that $\mathrm{BC}$ is not a homogeneous disease. Tumors in the breast have long been classified according to their morphologic features, histologic type, and grade (severity). Four major intrinsic subtypes have been identified by genomic studies: the luminal subtypes A and B, which express hormone receptor-related genes, basal-like (BL) BC, and HER2-positive BC. (4) More recently, gene expression analysis using DNA microarray technology has identified additional breast tumor subtypes that were not apparent using traditional histopathologic methods. Based on gene expression profiles, breast cancer can be classified into 5 main groups Luminal A, Luminal B ,Basal-like ,HER2 ,Normal breast-like. (5-6) Most breast cancers originate from the inner ("luminal") cells that line the mammary ducts. Luminal A and luminal B tumors are similar in that both are typically ER+ or PgR+, or both. However, they are dissimilar in that the A type is usually HER2- and the B type is more likely to be HER 2+ and lymph nodepositive. Women with luminal Atumors are often diagnosed at a younger age. They tend to have the best prognosis, with relatively high rates of overall survival and relatively low rates of recurrence. Those with luminal B tumorstend 
to have a higher tumour grade and a poorer prognosis (7-8). TNBC is a distinct breast cancer. It is classified into six groups based upon the GEP and DNA microarray. This sub-classification is not only useful in understanding the disease better but also to find molecular targets for its treatment (9).

\section{BL-1 and BL-2:-}

The BL-1 subtype was found to be composed rapidly dividing cells associated with increased proliferation and cell cycle checkpoint loss consistent with the increased expression of DNA damage response genes. Due to its high proliferation rate it has increased Ki67 mRNA expression and it is more responsiveness to antimitotic agents targeting cell cycle. The BL-2 subtype on the other hand displayed unique gene ontologies involving epidermal growth factor signaling as well as glycolysis and gluconeogenesis pathway. On microarray it showed a higher expression of epidermal growth factor receptor (EGFR), TP63, MET, etc.

\section{Immunomodulatory subtype:-}

Immunomodulatory (IM) is composed of immune cell responses such as immune cell and cytokine signaling, antigen presentation and processing and signaling of immune transduction pathways. Its GEP substantially overlaps with the medullary breast cancer, histologically a rare distinct form of TNBC which carry favorable prognosis despite its high grade.

\section{Mesenchymal and mesenchymal stem like subtype:-}

On GEP these subtypes consist of epithelial-mesenchymal (M) transition and growth factor pathways. The mesenchymal stem like subtype is also expressed by genes involved in angiogenesis including VEGFR2 and was found to be highly responsive to dasatinib [tyrosine kinase (TK) inhibitor], and mTOR inhibitors.

\section{Luminal androgen receptor subtype:-}

This subtype is characterized by androgen receptor (AR) signaling. It is ER negative but gene ontologies were heavily composed of hormonally regulated pathways such as steroid synthesis, porphyrin metabolism and androgen/estrogen metabolism. AR mRNA expression was nine times higher than other subtypes therefore, these lines were found to be highly sensitive to AR antagonists egbiclutamide. Patients with this subtype had decreased DFS and OS.

\section{Biomarkers in TNBC:-}

Identification of molecular markers such as expression of the estrogen (ER) and progesterone receptors (PgR) and the human epidermal growth factor receptor 2 (HER2) has offered additional predictive value for the therapeutic assessment of women diagnosed with breast cancer. TNBC is characterized by the marked expression of certain biomarkers. The presence of these molecules though is not restricted to TNBC but somehow show increased prevalence in this subgroup. The following are the important biomarkers in TNBC.

\section{Epidermal growth factor receptor (EGFR):-}

The four receptors being EGFR (or ErbB-1), HER-2/neu (ErbB-2), HER-3 (ErbB-3), and HER-4 (ErbB-4). The inactive monomer receptor dimerizes after ligand activation followed by TK, the intracellular domain of the receptor is activated by autophosphorylation, leading to a cascade of intracellular events (10). Epidermal growth factor receptor (EGFR) is a transmembrane tyrosine kinase receptor that plays a central role in regulating cell division and death. It belongs to the HER family of receptors, which includes EGFR (HER1/ErbB1), ERBB2 (HER2/neu), ERBB3 (HER3), and ERBB4 (HER4). These receptors are characterized by an extracellular ligand-binding domain, a transmembrane domain, and a cytoplasmic domain containing the tyrosine kinase region followed by a carboxyterminal tail with tyrosine autophosphorylation sites as depicted in figure 1 (Honey $\mathrm{V}$ et al: 1/10/2013 AACR) .EGFR signal cascade is important for cell proliferation, angiogenesis, metastatic spread, and the inhibition of apoptosis. Most of the TNBCs express EGFR, and poses a strong therapeutic challenge (11). 


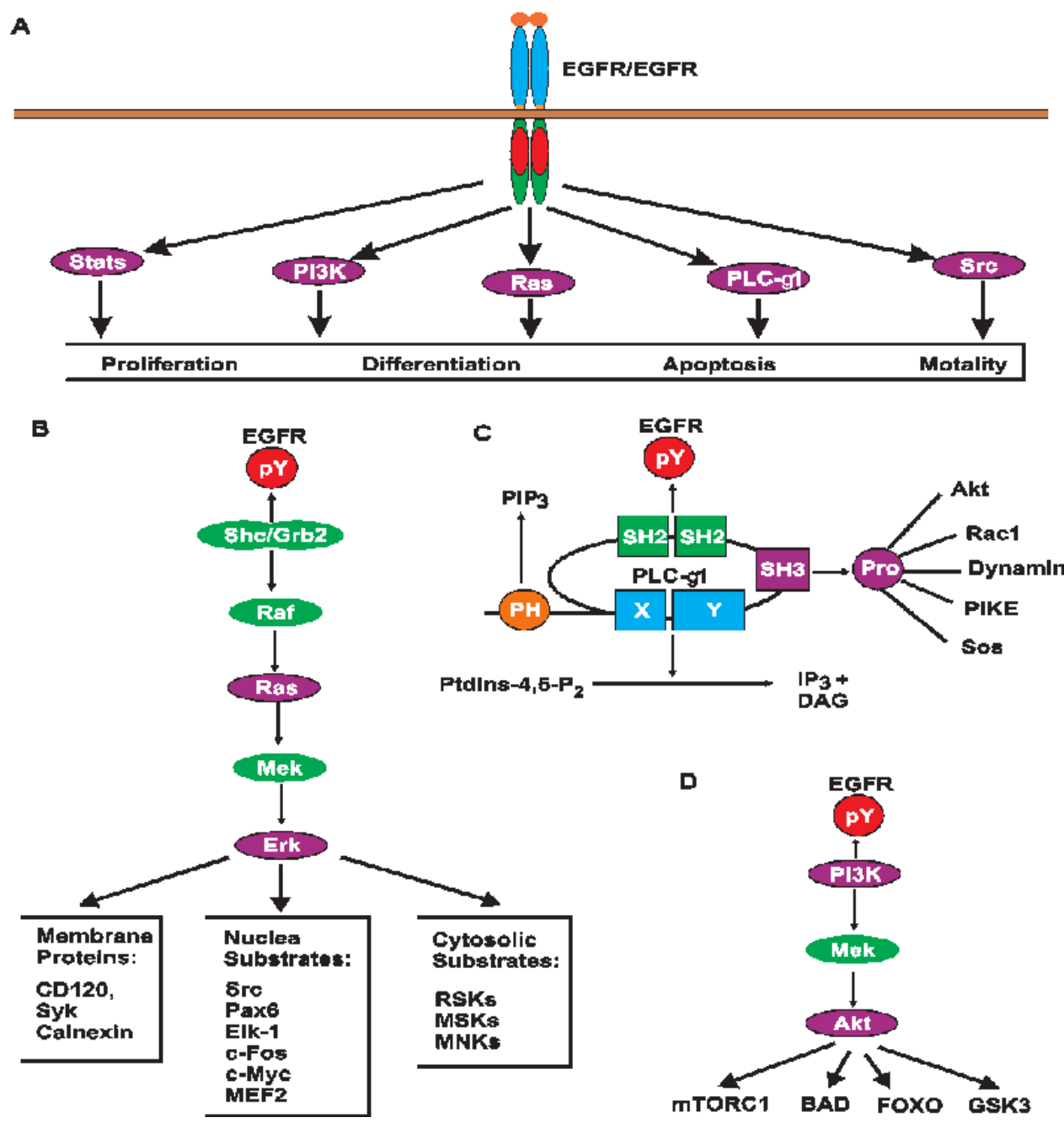

Figure 1:-Honey V et al: 1/10/2013 AACR.

EGFR expression is found in $40 \%-50 \%$ of patients with breast cancer and in $80 \%$ of TNBC; and is estimated to substitute major proliferation pathways of breast cancer induced by activation of HER-2, ER, PR proteins which are thereby absent in TNBC(12). EGFR expression in TNBC is associated with poor response to chemotherapy (13).Nogi et al (14).observed that EGFR was expressed in $24 \%$ of the TNBC patients and was related to less favorable response to chemotherapy and poorer survival and on the contrary the luminal groups where EGFR expression showed a good response to chemotherapy and better survival. Recently EGFR has been defined with other markers to differentiate BL subtype from TNBC (15).Epidermal growth factor receptor (EGFR) is more frequently expressed in TNBCs than in non-TNBCs. Therefore, the EGFR is considered a candidate treatment target for TNBCs.TNBCs have an aggressive clinical course, and EGFR might be candidate therapeutic targets in this disease. This aids in segregating TNBC into subtypes and thus defining the prognostic difference and molecular target specification between the two. So EGFR is a biomarker in TNBC and a target for cetuximab, a TK inhibitor.

Vascular endothelial growth factor:-

High VEGFR2 expression, EGFR expression, and EGFR gene copy number were significantly correlated to TNB, supporting their role as putative candidate biomarkers for selection of targeted therapy in TNB. Vascular endothelial growth factor (VEGF-A) is considered a prognostic indicator for clinical outcome in breast cancer.Angiogenesis is important for tumor growth and spread especially beyond a diameter of $2 \mathrm{~mm}$ as oxygen and nutrients cannot diffuse beyond this distance. Angiogenic signals are mediated by vascular endothelial growth factor (VEGF) to aid neovascularisation. VEGF protein is found in 4 isoforms because of alternative splicing of its mRNA(16). Among the different isoforms VEGF165, the 165-amino acid molecule is more common (17). Its gene 
expression is controlled by many of stimuli such as hypoxia, nitric oxide, growth factors, oncogenes, tumor suppressor genes and HER-2 (18). Vascular endothelial growth factor A (VEGF-A) and vascular endothelial growth factor receptor 2 (VEGFR2) are often coexpressed in breast cancer, and potentially affect cellular pathways and key proteins such as the estrogen receptor (ER) targeted by endocrine treatment. In TNBC higher VEGF levels are associated with shorter DFS, OS, and DDFS. Also, VEGF levels have been significantly related to the size of the tumor, grade and metastatic sites. In patients with higher VEGF levels disease progressed despite of therapy and such patients were associated with significantly lower progression free survival as compared to patients with lower levels. In TNBC patients it was found that VEGF level elevated from baseline to middle of the therapy significantly but showed a non significant increase from the middle of the therapy to its end when patients were administered FAC(19). VEGF is a target for bevacizumab in TNBC patients. High VEGFR2 expression was significantly correlated to decreased BCSS in TNB patients. TNB was associated with decreased BCSS and clinicopathological characteristics of an aggressive tumor type. High VEGFR2 expression was significantly correlated to TNB, supporting their role as putative candidate biomarkers for selection of targeted therapy in TNB (20).

\section{Poly(ADP-ribose) polymerase (PARP):-}

The discovery of poly(ADP-ribose) >50 years ago opened a new field, leading the way for the discovery of the poly(ADP-ribose) polymerase (PARP) family of enzymes and the ADP-ribosylation reactions that they catalyze. Although the field was initially focused primarily on the biochemistry and molecular biology of PARP-1 in DNA damage detection and repair, the mechanistic and functional understanding of the role of PARPs in different biological processes has grown considerably of late. PARPs are a family of cell signaling enzymes present in eukaryotes, which catalyzes the poly(ADP-ribosylation) of DNA binding proteins (21-22). Till now eighteen enzymes of $P A R P S$ has been detected, but $P A R P 1$ the most common isoform. $P A R P 1$ is responsible for the majority of its functions. The main function of $P A R P 1$ is as DNA damage nick sensor. It forms polymers of ADP-ribose and nicotinamide with the use of $\mathrm{NAD}^{+}$. Activation of $P A R P 1$ is important in tumors because of three interesting biological reasons: First, it plays a vital role in DNA repair through base excision repair pathway; second, it is capable of depleting cellular energetic pools, which results in cell dysfunction and necrosis; and third, its ability to promote the transcription of proinflammatory genes. PARP enzymes are involved in cellular response to inflammation, ischemia and oxidative stress. PARPI are involved in all these cellular processes, indicating the possible link between $P A R P 1$ function and carcinogenesis (23). BRCA2 operates through excision repair pathway like $B R C A 1$, mutation of this gene make the cells susceptible to $P A R P$ inhibitors as well (24,25). $P A R P$ also plays a vital role in DNA repair as $B R C A$. Unlike $B R C A$ it recognizes $\mathrm{SSBs}$ and repairs by base excision repair pathway. PARP inhibitors are effective in TNBC because damage to one of the arms of the DNA could not be repaired by homologous recombination due to $B R C A$ mutation and $P A R P$ inhibition in synergism will create a state of "synthetic lethality" - a process that occurs when inactivation of individual genes have no effect but mutations in both the genes lead to death of cancer cells (26). So BRCA mutation is responsible for the action of many chemotherapeutic agents in TNBC. The inhibition of PARP1 is also known to potentiate the effect of ionizing radiation and many drugs such as DNA methylating agents, topoisomerase Iinhibitors, and platinum compounds. Studies in mouse models have shown that the addition of PARP inhibitors with platinum compounds increases RFS and OS (27) while many of other studies on cell lines reveal that the activity of PARP inhibitors was increased in presence of BRCA mutations or dysfunction (28). PARPl has been targeted as therapeutic option in TNBC with drugs like iniparib, olaparib etc though not found to be independently helpful but their addition to cytotoxic agents have surely brought synergism to their activity and improvement in treatment response in TNBC patients

\section{MicroRNAs Biomarkers:-}

To date, the treatment strategies for TNBC are limited to surgery, chemotherapy and radiation, owing to the lack of effective therapeutic targets. Therefore, it is important to identify specific targets for TNBCs. MicroRNAs (miRNAs), a family of small non-coding RNAs regulating gene expression, are an emerging class of regulators of various biological processes, including cell proliferation, invasion, epithelial-mesenchymal transition (EMT) and drug resistance. Actually, miRNAs may serve as a novel therapeutic target in TNBC. In a more recent study, 34 miRNAs were observed to be significantly differentially expressed among the luminal A, HER2-amplified and triple negative cell lines (29), and the biologic profiling of miRNA signatures for different subtypes were also extensively explored in breast cancer tissue samples (30,31). It was functionally demonstrated that miR-498 inhibits BRCA1 in breast cancer cell lines, and showed that inhibition of miR-498 led to reduced proliferation in the triple negative cell line Hs578T and results indicate that miR-498 regulates BRCA1 expression in breast cancer and its overexpression could contribute to the pathogenesis of sporadic TNBC via BRCA1 downregulation. 
MiR-21 (oncomiR)-miR-21 an oncomiR was proven to regulate PTEN by targeting the mRNA 3'UTR, leading to an anti-apoptosis effect in TNBC (32). Specifically, miR-21 exhibits a higher expression level in TNBC than nonTNBC, and it is positively correlated with a poor clinical outcome.

miR-203 (oncosuppressor)-In contrast to the miRNAs afore-mentioned, miR-203 is an oncosuppressormiRNA which plays a specific metastatic suppressor role by targeting LASPl in TNBC, it can significantly inhibit cell proliferation by regulating BIRC5 (33). Thus, the miRNAs controlling the expression of quite a few key genes are likely to affect tumor behavior and progression in TNBC. With the improvement of tumor biology understanding, an increasing number of known miRNAs have been identified to be prognostic in TNBC. Inverse correlation between miR-27b and distant relapse-free survival (DRFS) was found by performing miRNA expression profiles, while miR342 and miR-150 were correlated with better prognosis (34).

There are some miRNAs, such as miR-210 (35), miR-155 (36), miR-27b-3p (37), miR-34b (38) and miR-21 (39), that could to be poor prognosis indicators in TNBC. It is worth mentioning that the protective miR-497,was identified downregulated in TNBC vs. both normal tissue and non-TNBC cells (40), indicating its putative positive effect against aggressive malignant phenotype in TNBC. The miR-210, was up-modulated in TNBC vs. both normal and non-TNBC tissues, thereby, providing a potential therapeutic target for TNBC.

\section{C-kit and basal cytokeratins:-}

$\mathrm{C}$-kit is a cytokine receptor present on the surface of hematopoietic stem cells and also in other cells. C-kit binds to stem cell factor and is a growth factor receptor that stimulates major cellular functions such as cell survival, proliferation, differentiation, adhesion and chemotaxis. It induces apoptosis and also increases the invasiveness of the cancer cells (41).KIT plays a critical role in cell proliferation and differentiation and represents a logical therapeutic target in GIST and CML. The study of the CK profile by IHC techniques is very important for tumor pathologic classification (42). CKs were earlier used to distinguish malignant breast lesions from benign ones (43), but later their prognostic value was ascertained and it was seen that expression of CK-5, CK-14 and CK-17 was related to poor prognosis, high grade tumors, ER negativity, short DFS and OS (44). It is expressed in BLBCs. Since BLBC and TNBC show overlapping features therefore C-kit and basal CKs along with other markers and pathological features are used for the differentiating BLBCs from TNBC. Many studies have revealed that presence of CKs is higher in TNBC than non-TNBC and also among TNBC subgroup it is higher in the BL subclass. BL subclass of TNBC was identified on the basis of CK and EGFR expression and when the clinicopathological features were compared between the basal and non-BL it was seen that BL subclass of TNBC was more aggressive (45).

\section{The Ki-67 protein (also known as MKI67):-}

Antigen KI-67 is a nuclear protein that is associated with and may be necessary for cellular proliferation. Furthermore, it is associated with ribosomal RNA transcription. Inactivation of antigen KI-67 leads to inhibition of ribosomal RNA synthesis. Ki67 is a cellular marker for proliferation. Ki67 antigen is present inside the cell nucleus during interphase and during mitosis it is relocated to the surface of the chromosomes. Since it is a marker of proliferation it is found in all cells when they are in dividing phases of the cell cycle $\left(G_{1}, S, G_{2}\right.$, and mitosis) and it is absent from cells during their resting phase $\left(\mathrm{G}_{0}\right)$. Its absence in resting cells and generalized presence in dividing cells had made it a marker of cell proliferation (46). Proliferation is a salient feature for the spread of cancer and can be assessed by the IHC measurement of the nuclear antigen Ki67. It's over expression also correlates with levels of bromodeoxyuridine uptake and S-phase fraction, other markers of proliferation.Ki67 expression is less in normal breast tissue $(<3 \%)$. Recently it has been reported in many studies that Ki67 antigen and steroid-receptor are expressed in different cells in normal human breast epithelium. Ki67 was over expressed particularly in ER-negative cells and its expression in carcinoma cells was much higher (47-48). In TNBC, it was found that Ki67 levels were significantly increased in ductal TNBC compared to other histologic types $(80 \%$ in TNBC vs $10 \%$ - $30 \%$ in other types). Its expression also represented a direct co relation with tumor size and grade in TNBC patients and higher levels (> 35\% staining) were linked with an increased risk of death (49-51). In TNBC patients Ki67 accumulation was associated with a higher pCR to chemotherapy but poor RFS and OS. Its expression was also used for subdivision of TNBC into two subtypes where only $26.7 \%$ of TNBC patients showed lower Ki67 expression (52).

\section{DNA topoisomerase 2-alpha:-}

Amplification or deletion of the topoisomerase II alpha (TOP2A) gene in breast cancers has been postulated to be more closely associated with responsiveness to anthracycline-containing chemotherapy than amplification of the 
human epidermal growth factor receptor type 2 (HER2) gene. Patients with TOP2A overexpression have a worse prognosis compared with those with TOP2A nonexpression, and TOP2A may be a useful biomarker in patients receiving adjuvant taxane-platinum regimens with moderate- to high-risk endometrial cancer (53-54).DNA topoisomerase 2-alpha is an enzyme that in humans are encoded by the TOP $2 A$ gene. This gene encodes a DNA topoisomerase, an enzyme that controls and alters the topologic states of DNA during transcription. This nuclear enzyme is involved in processes such as chromosome condensation, chromatid separation, and the relief of torsional stress that occurs during DNA transcription and replication. It catalyzes the transient breaking and rejoining of two strands of duplex DNA which allowthe strands to pass through one another, thus altering the topology of DNA. Two forms of this enzyme exist as likely products of a gene duplication event. The gene encoding this form, alpha, is localized to chromosome 17 and the beta gene is localized to chromosome 3 . The gene encoding this enzyme functions as the target for several anticancer agents and a variety of mutations in this gene have been associated with the development of drug resistance. Reduced activity of this enzyme may also play a role in ataxia-telangiectasia (55). In TNBC or breast carcinoma the gene acts as a target for anthracycline therapy which is a topoisomerase II inhibitor (56). So it is a marker for the evaluation of resistance to the anthracycline therapy. A study revealed a higher expression of TOP-2A in $2.7 \%$ to $8.8 \%$ of TNBC patients (57).Its over expression in TNBC leads to the decreased sensitivity towards the anthracyclines and thus decreased response. TOP2A expression is a marker of the tumor's proliferation rate and sensitivity to anthracycline-based chemotherapy, and does not depend on the amplification of its gene.

\section{MAP kinase pathway:-}

Mitogen-activated protein kinase (MAPK) pathways are evolutionarily conserved kinase modules that link extracellular signals to the machinery that controls fundamental cellular processes such as growth, proliferation, differentiation, migration and apoptosis (58).MAPK pathways are comprised of a three-tier kinase module in which a MAPK is activated upon phosphorylation by a mitogen-activated protein kinase kinase (MAPKK), which in turn is activated when phosphorylated by a MAPKKK. To date six distinct groups of MAPKs have been characterized in mammals; extracellular signal-regulated kinase (ERK)1/2, ERK3/4, ERK5, ERK7/8, Jun N-terminal kinase $(\mathrm{JNK}) 1 / 2 / 3$ and the $\mathrm{p} 38$ isoforms $\propto / \beta / \gamma(\mathrm{ERK} 6) / \delta(\mathbf{5 9})$. The mitogen-activated protein (MAP) kinase cell signaling pathway promotes cell growth, proliferation, and survival. The MAP kinase pathway may be activated via several different routes, including upstream growth factorreceptortyrosine kinases and downstream mutations in pathway gene components(60). The MAP kinase pathway has also been evaluated as a potential target in TNBC, with corresponding biomarker studies performed. Preclinical evaluation of 21 breast cancer cell lines treated with MEK1/2 inhibitor trametinib demonstrated the greatest sensitivity in the 11 TNBC cell lines evaluated. The authors ultimately identified DUSP6, a phosphatase that decreases pERK2 activity upon MAPK pathway activation, as a potential marker of sensitivity to the drug. Expression of this gene was associated with greater sensitivity to trametinib in multiple solid tumor cell lines, though was not evaluated in the breast cancer models (59). Mutations that serve as targets for currently available agents, including EGFR, HER2, KRAS, and BRAF mutation as well as EML4-ALK fusion and EGFR copy gain have also been studied in TNBC. Of 65 TNBC specimens, the only abnormalities identified were a HER2 mutation in one patient and EGFR gene amplification in a second patient (61).This suggests little utility for use of these mutations as biomarkers or as potential targets for therapy.These numerous studies are encouraging in their efforts to identify biomarkers for TNBC in the setting of novel targeted agent development. However, the best data for any of these biomarkers has still been developed in only small preclinical or retrospective studies. There is hope that these promising findings will be further evaluated in large, prospective trials, and that coordinated drug and biomarker development may be central to such trials in the future.

\section{Conclusion:-}

Evaluation of biomarkers for currently available chemotherapeutic agents should focus on the mechanism and characteristics of each agent separately, rather than on chemotherapy in general. With these changes in the development of predictive biomarkers for TNBC comes the possibility for exciting advances in this field for the future. TNBC is the most poorly understood and is refractory to current targeted therapies. It is a cause of significant breast cancer mortality because of very few treatment options. A biomarker may be useful as prognostic or predictive indicators as well as suggest possible targets for novel therapies.

\section{Acknowledgment:-}

We acknowledge the support of Dr AB Rashid Mir Assistant Professor, Prince Fahd Bin Sultan Research chair , Supervisor- Division of Cancer Molecular Genetics, University of Tabuk. 


\section{Disclosure:-}

The authors report no conflict of interest in this work.

\section{References:-}

1. Torre LA, Bray F, Siegel RL, Ferlay J, Lortet-Tieulent J, Jemal A. Global cancer statistics, 2012. CA Cancer J Clin. 2015;65(2):87-108

2. Perou CM, Sørlie T, Eisen MB, et al. Molecular portraits of human breast tumours. Nature. 2000;406(6797):747-752

3. P. Boyle .Triple-negative breast cancer: epidemiological considerations and recommendations . Ann Oncol (2012) 23 (suppl_6): vi7-vi12

4. Sørlie T, Perou CM, Tibshirani R, et al. Gene expression patterns of breast carcinomas distinguish tumor subclasses with clinical implications. Proc NatlAcadSci U S A. 2001;98(19):10869-108-74

5. Brenton JD, Carey LA, Ahmed AA, Caldas C. Molecular classification and molecular forecasting of breast cancer: ready for clinical application? J ClinOncol. 2005;23:7350-60.

6. Reis-Filho JS, Westbury C, Pierga JY. The impact of expression profiling on prognostic and predictive testing in breast cancer. J ClinPathol. 2006;59:225-31.

7. Calza S, Hall P, Auer G, et al. Intrinsic molecular signature of breast cancer in a population-based cohort of 412 patients. Breast Cancer Res. 2006;8:R34.

8. Carey LA, Perou CM, Livasy CA, et al. Race, breast cancer subtypes, and survival in the Carolina Breast Cancer Study. JAMA. 2006;295:2492-502.

9. Lehmann BD, Bauer JA, Chen X, Sanders ME, Chakravarthy AB, Shyr Y, Pietenpol JA. Identification of human triple-negative breast cancer subtypes and preclinical models for selection of targeted therapies. J Clin Invest. 2011;121:2750-2767

10. Siziopikou KP, Cobleigh M. The basal subtype of breast carcinomas may represent the group of breast tumors that could benefit from EGFR-targeted therapies. Breast. 2007;16:104-107

11. Bhargava R, Gerald WL, Li AR, Pan Q, Lal P, Ladanyi M, Chen B. EGFR gene amplification in breast cancer: correlation with epidermal growth factor receptor mRNA and protein expression and HER-2 status and absence of EGFR-activating mutations. Mod Pathol. 2005;18:1027-1033.

12. Bidard FC, Conforti R, Boulet T, Michiels S, Delaloge S, André F. Does triple-negative phenotype accurately identify basal-like tumour? An immunohistochemical analysis based on 143 'triple-negative' breast cancers. Ann Oncol. 2007;18:1285-1286.

13. Rakha EA, El-Sayed ME, Green AR, Lee AH, Robertson JF, Ellis IO. Prognostic markers in triple-negative breast cancer. Cancer. 2007;109:25-32.

14. Nogi H, Kobayashi T, Suzuki M, Tabei I, Kawase K, Toriumi Y, Fukushima H, Uchida K. EGFR as paradoxical predictor of chemosensitivity and outcome among triple-negative breast cancer. Oncol Rep. 2009;21:413-417.

15. Mehdizadeh R, Nazafi S, Jahanjad I. Evaluation of EGFR, VEGFR2, IGF-1R, and HIF-1a expression and their prognostic value in Iranian triple negative breast cancer patients. EJC. 2012;48:S145.

16. Achen MG, Stacker SA. The vascular endothelial growth factor family; proteins which guide the development of the vasculature. Int J Exp Pathol. 1998;79:255-265

17. Ferrara N. Role of vascular endothelial growth factor in the regulation of angiogenesis. Kidney Int. 1999;56:794-814.

18. Benjamin LE, Keshet E. Conditional switching of vascular endothelial growth factor (VEGF) expression in tumors: induction of endothelial cell shedding and regression of hemangioblastoma-like vessels by VEGF withdrawal. Proc NatlAcadSci USA. 1997;94:8761-8766.

19. Linderholm BK, Hellborg H, Johansson U, Elmberger G, Skoog L, Lehtiö J, Lewensohn R. Significantly higher levels of vascular endothelial growth factor (VEGF) and shorter survival times for patients with primary operable triple-negative breast cancer. Ann Oncol. 2009;20:1639-1646

20. Rydén L, Jirström K, Haglund M, Stål O, Fernö.Epidermal growth factor receptor and vascular endothelial growth factor receptor 2 are specific biomarkers in triple-negative breast cancer. Results from a controlled randomized trial with long-term follow-up.Breast Cancer Res Treat. 2010 Apr;120(2):491-8

21. Qiu WG, Polotskaia A, Xiao G, Di L, Zhao Y, Hu W, Philip J, Hendrickson RC, BargonettiJ.NPJ.Identification, validation, and targeting of the mutant p53-PARP-MCM chromatin axis in triple negative breast cancer.Breast Cancer. 2017;3.

22. Qiao W, Pan L, Kou C, Li K, Yang M.Prognostic and clinicopathological value of poly (adenosine diphosphateribose) polymerase expression in breast cancer: A meta-analysis.PLoS One. 2017 Feb 17;12(2):e0172413 
23. Fong PC, Boss DS, Yap TA, Tutt A, Wu P, Mergui-Roelvink M, Mortimer P, Swaisland H, Lau A, O’Connor $\mathrm{MJ}$, et al. Inhibition of poly(ADP-ribose) polymerase in tumors from BRCA mutation carriers. $\mathrm{N}$ Engl J Med. 2009;361:123-134

24. Bryant HE, Schultz N, Thomas HD, Parker KM, Flower D, Lopez E, Kyle S, Meuth M, Curtin NJ, Helleday T. Specific killing of BRCA2-deficient tumours with inhibitors of poly(ADP-ribose) polymerase. Nature. 2005;434:913-917

25. Evers B, Drost R, Schut E, de Bruin M, van der Burg E, Derksen PW, Holstege H, Liu X, van Drunen E, Beverloo HB, et al. Selective inhibition of BRCA2-deficient mammary tumor cell growth by AZD2281 and cisplatin. Clin Cancer Res. 2008;14:3916-3925

26. Bhattacharyya A, Ear US, Koller BH, Weichselbaum RR, Bishop DK. The breast cancer susceptibility gene BRCA1 is required for subnuclear assembly of Rad51 and survival following treatment with the DNA crosslinking agent cisplatin. J Biol Chem. 2000;275:23899-23903

27. Hastak K, Alli E, Ford JM. Synergistic chemosensitivity of triple-negative breast cancer cell lines to poly(ADPRibose) polymerase inhibition, gemcitabine, and cisplatin. Cancer Res. 2010;70:7970-7980

28. . Farmer H, McCabe N, Lord CJ, Tutt AN, Johnson DA, Richardson TB, Santarosa M, Dillon KJ, Hickson I, Knights C, et al. Targeting the DNA repair defect in BRCA mutant cells as a therapeutic strategy. Nature. 2005;434:917-921.

29. Mackiewicz M, Huppi K, Pitt JJ, Dorsey TH, Ambs S and Caplen NJ: Identification of the receptor tyrosine kinase AXL in breast cancer as a target for the human miR-34a microRNA. Breast Cancer Res Treat. 130:663679. 2011

30. Janssen EA, Slewa A, Gudlaugsson E, et al: Biologic profiling of lymph node negative breast cancers by means of microRNA expression. Mod Pathol. 23:1567-1576. 2010

31. Farazi TA, Ten Hoeve JJ, Brown M, et al: Identification of distinct miRNA target regulation between breast cancer molecular subtypes using AGO2-PAR-CLIP and patient datasets. Genome Biol. 15:R92014

32. Dong G, Liang X, Wang D, et al: High expression of miR-21 in triple-negative breast cancers was correlated with a poor prognosis and promoted tumor cell in vitro proliferation. Med Oncol. 31:572014

33. Wang C, Zheng X, Shen C and Shi Y: MicroRNA-203 suppresses cell proliferation and migration by targeting BIRC5 and LASP1 in human triple-negative breast cancer cells. J Exp Clin Cancer Res. 31:582012

34. Buffa FM, Camps C, Winchester L, et al: microRNA-associated progression pathways and potential therapeutic targets identified by integrated mRNA and microRNA expression profiling in breast cancer. Cancer Res. 71:5635-5645. 2011

35. Toyama T, Kondo N, Endo Y, et al: High expression of microRNA-210 is an independent factor indicating a poor prognosis in Japanese triple-negative breast cancer patients. Jpn J ClinOncol. 42:256-263. 2012.

36. Kong W, He L, Richards EJ, et al: Upregulation of miRNA-155 promotes tumour angiogenesis by targeting VHL and is associated with poor prognosis and triple-negative breast cancer. Oncogene. 33:679-689. 2014

37. Shen S, Sun Q, Liang Z, et al: A prognostic model of triple-negative breast cancer based on miR-27b-3p and node status. PLoS One. 9:e1006642014.

38. Svoboda M, Sana J, Redova M, et al: MiR-34b is associated with clinical outcome in triple-negative breast cancer patients. DiagnPathol. 7:312012

39. Avery-Kiejda KA, Braye SG, Mathe A, Forbes JF and Scott RJ: Decreased expression of key tumour suppressor microRNAs is associated with lymph node metastases in triple negative breast cancer. BMC Cancer. $14: 512014$

40. Radojicic J, Zaravinos A, Vrekoussis T, Kafousi M, Spandidos DA and Stathopoulos EN: MicroRNA expression analysis in triple-negative (ER, PR and Her2/neu) breast cancer. Cell Cycle. 10:507-517. 2011

41. Andre F, Job B, Dessen P, Tordai A, Michiels S, Liedtke C, Richon C, Yan K, Wang B, Vassal G, et al. Molecular characterization of breast cancer with high-resolution oligonucleotide comparative genomic hybridization array. Clin Cancer Res. 2009;15:441-451.

42. Edling CE, Hallberg B. c-Kit--a hematopoietic cell essential receptor tyrosine kinase. Int J Biochem Cell Biol. 2007;39:1995-1998.

43. Schweizer J, Bowden PE, Coulombe PA, Langbein L, Lane EB, Magin TM, Maltais L, Omary MB, Parry DA, Rogers MA, et al. New consensus nomenclature for mammalian keratins. J Cell Biol. 2006;174:169-174.

44. Otterbach F, Bànkfalvi A, Bergner S, Decker T, Krech R, Boecker W. Cytokeratin 5/6 immunohistochemistry assists the differential diagnosis of atypical proliferations of the breast. Histopathology. 2000;37:232-240.

45. Abd El-Rehim DM, Pinder SE, Paish CE, Bell J, Blamey RW, Robertson JF, Nicholson RI, Ellis IO. Expression of luminal and basal cytokeratins in human breast carcinoma. J Pathol. 2004;203:661-671 
46. Urruticoechea A, Smith IE, Dowsett M. Proliferation marker Ki67 in early breast cancer. J ClinOncol. 2005;23:7212-7220.

47. Zhou CJ, Zhang QH, Zhang TG, Sun SZ, Li H, Wang Y, Liu ZY. Expression of ER, Ki67 and cylinD1 in the pre-cancerous breast of Chinese patients. PatholOncol Res. 2009;15:153-158.

48. Harvey JA, Santen RJ, Petroni GR, Bovbjerg VE, Smolkin ME, Sheriff FS, Russo J. Histologic changes in the breast with menopausal hormone therapy use: correlation with breast density, estrogen receptor, progesterone receptor, and proliferation indices. Menopause. 2008;15:67-73.

49. Fasching PA, Heusinger K, Haeberle L, Niklos M, Hein A, Bayer CM, Rauh C, Schulz-Wendtland R, Bani MR, Schrauder M, et al. Ki67, chemotherapy response, and prognosis in breast cancer patients receiving neoadjuvant treatment. BMC Cancer. 2011;11:486.

50. Tanei T, Shimomura A, Shimazu K, Nakayama T, Kim SJ, Iwamoto T, Tamaki Y, Noguchi S. Prognostic significance of Ki67 index after neoadjuvant chemotherapy in breast cancer. Eur J SurgOncol. 2011;37:155161.

51. Selz J, Stevens D, Jouanneau L, Labib A, Le Scodan R. Prognostic value of molecular subtypes, ki67 expression and impact of postmastectomy radiation therapy in breast cancer patients with negative lymph nodes after mastectomy. Int J RadiatOncolBiol Phys. 2012;84:1123-1132.

52. Keam B, Im SA, Lee KH, Han SW, Oh DY, Kim JH, Lee SH, Han W, Kim DW, Kim TY, et al. Ki67 can be used for further classification of triple negative breast cancer into two subtypes with different response and prognosis. Breast Cancer Res. 2011;13:R22

53. Ito F, Furukawa N, NakaiT.Evaluation of TOP2A as a Predictive Marker for Endometrial Cancer With TaxaneContaining Adjuvant Chemotherapy.Int J Gynecol Cancer. 2016 Feb;26(2):325-30.

54. Nikolényi A ${ }^{1}$, Sükösd F, Kaizer L, Csörgo E, Vörös A, Uhercsák G, Ormándi K, Lázár G, Thurzó L, Brodowicz T, KahánZ.Tumor topoisomerase II alpha status and response to anthracycline-based neoadjuvant chemotherapy in breast cancer.Oncology. 2011;80(3-4):269-77.

55. Watt PM, Hickson ID (1994). "Structure and function of type II DNA topoisomerases.". Biochem. J. 303 (3): 681-95

56. Burgess DJ, Doles J, Zender L, Xue W, Ma B, McCombie WR, Hannon GJ, Lowe SW, Hemann MT. Topoisomerase levels determine chemotherapy response in vitro and in vivo. Proc NatlAcadSci USA. 2008;105:9053-9058.

57. Knoop AS, Knudsen H, Balslev E, Rasmussen BB, Overgaard J, Nielsen KV, Schonau A, Gunnarsdóttir K, Olsen KE, Mouridsen $\mathrm{H}$, et al. retrospective analysis of topoisomerase IIa amplifications and deletions as predictive markers in primary breast cancer patients randomly assigned to cyclophosphamide, methotrexate, and fluorouracil or cyclophosphamide, epirubicin, and fluorouracil: Danish Breast Cancer Cooperative Group. J ClinOncol. 2005;23:7483-7490.

58. Weigelt B, Horlings HM, Kreike B, Hayes MM, Hauptmann M, Wessels LF, de Jong D, Van de Vijver MJ, Van't Veer LJ, Peterse JL. Refinement of breast cancer classification by molecular characterization of histological special types. J Pathol. 2008;216:141-150

59. Bradham C, McClay DR. (2006). p38 MAPK in development and cancer. Cell Cycle 5: 824-828.

60. Brancho D, Tanaka N, Jaeschke A, Ventura JJ, Kelkar N, Tanaka Y et al. (2003). Mechanism of p38 MAP kinase activation in vivo. Genes Dev 17: 1969-1978.

61. Jing J, Greshock J, Holbrook JD, Gilmartin A, Zhang X, McNeil E, Conway T, Moy C, Laquerre S, Bachman K, Wooster R, DegenhardtY.Comprehensive predictive biomarker analysis for MEK inhibitor GSK1120212.Mol Cancer Ther. 2012 Mar; 11(3):720-9.

62. Grob TJ, Heilenkötter U, Geist S, Paluchowski P, Wilke C, Jaenicke F, Quaas A, Wilczak W, Choschzick M, Sauter $G$, LebeauA.Rare oncogenic mutations of predictive markers for targeted therapy in triple-negative breast cancer.Breast Cancer Res Treat. 2012 Jul; 134(2):561-7. 